\title{
Text Interpretation: Intention or Convention?
}

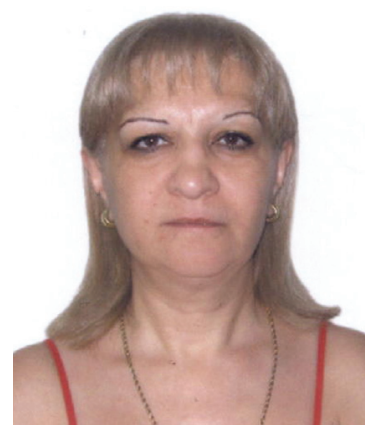

Gayane Gasparyan ny utterance performed in a certain situation is a unit
of communicative act between the one who pro-
duces it as a message to be sent to someone who receives it.
The communicative intention in utterance is of great impor-
tance and, if the latter is correctly performed by the one who
"sends" this message, it will be hereby recognized by the one
who receives it. So the language media must be selected and
arranged in such a way, that the intention becomes recogniz-
able in the situation where the communicative act is taking
place.
You may ask, whether it is really so important for the
intention to be recognized. And the answer will be, yes indeed, especially if the message is uttered orally, as it needs a certain reaction on the part of the one who is to receive it. In this case if the intention is recognized by your communicant the reaction will be correctly performed and you will achieve the desirable effect. This is the so called reflexive intention, characterized by H.P. Grice (Grice 1989) as a leading parameter in communicative act when the fulfillment of an intention consists in its recognition. Though, the partisans of J.L. Austin's theory (Austin 1962) would try to argue confirming you that the speakers' intentions and the hearers' inferences do not occupy the central position in communicative act, the success of which is achieved by the matter of convention and not intention. On the other hand, another group of scholars led by P.F. Strawson (Strawson 1964) would argue J.L. Austin's attempts to force convention into a leading position within the act of communication considering this type of utterances to be a special case that affect institutional states, which should not be generalized in any case, as for J.L. Austin whatever the speaker is doing is creating social realities within certain social contexts. They would state that these acts would be successfully performed in certain conventionally designated circumstances and by people in certain positions that certain utterances can have the force they do. According to J. Searle whatever people talk or write to each other, they are performing illocutionary acts, which in their turn are performed with intentionality, and this act may be communicatively successful if the illocutionary intention is recognized and achieves some perlocutionary effect (Searle 1969). J. Searle believes that the number of things which can be done with language is limited, whereas the potential propositional content is limitless. This is how different approaches towards speech acts may be briefly defined.

Anyhow, if a literary text is viewed as a certain type of utterance it becomes a unit of communication and may be defined within the terms of speech act theory and therefore acquires the qualitative features of the latter. The leading among them is considered to be intentionality which any text contains as its integral component, including besides the linguistic information a system of communicative presumptions and certain contextual circumstances for mutual understanding. The communicative act hereby will become successful in case the intention is recognized by the reader. 
Let the process of recognition of the intention be termed as interpretation which in its turn may be defined as a certain type of cognitive activity very much depending upon the ability of both communicants (the author and the reader) to perceive, reconstruct and reproduce the reality itself (Gasparyan 2007). It is a two-sided process and two types of interpretation take place within this specific communicative act. First the author of the text perceives the reality as he/she only can do it, reconstructs and then reproduces it according to his/her specific manner of interpreting this reality. Whenever the text starts its extra-textual (out-of-text) circulation the same process is taking place on the reader's part. First the out-of-text reality is perceived and reconstructed by the reader then the inside-the-text reality is interpreted according to his/her ability to find the so-called "global" coherence of both inside and outside situations. Anyway, if the author-reader propositional content coincides, the intention becomes recognizable and the pragmatic efforts of the author are crowned by a correct interpretation.

Again you may ask: what would happen if the author-reader propositional content does not coincide, and the answer will be: it happens very often, when the pragmatic directives do not stimulate the desirable image, then the intention becomes unrecognizable. It happens especially when the author-reader cognitive environment does not coincide. In this case the cognitive process of the reader's/author's perception, reconstruction and interpretation of the reality itself will not coincide, and the reader's interpretation of the inside-the-text reality will deviate from that of the author's one. Though, if another cognitive activity on the reader's part and that is recognizing because of certain knowledge, comes into force the result will be apparent. If the reader has a certain portion of background information about the context in its broadest sense where, how and why the text was created as a means of communicative act, then its interpretation will be more or less adequate and the intention will become recognizable. In this case the communicative act may be considered successful and will contain mutual understanding as a result.

The certain knowledge of background information is very much important especially if the text represents a vivid picture of nationally oriented phenomena. In this case the cultural principles of text interpretation will come to be used. If the background knowledge includes all the necessary information about the author, his/her culture and the cognitive environment this culture creates, it will make the author's intention recognizable.

Thus, to interpret the title of W. Saroyan's story "Antranik of Armenia" correctly one should be able to grasp the deeper layers of its semantic and syntactical structure. To do that the reader is forced to collect a certain portion of information about the two chief elements of the title - Antranik and Armenia, if he/she is not of course an Armenian. $\mathrm{He} / \mathrm{she}$ is to know first what Armenia is to be able to distinguish whether it is a country, a city, a village, or whatever else. As soon as the reader gets the necessary information about this element of the title he/she goes further to find out what Antranik is, as it is the first element of the title (hence written with a capital letter) and a number of nonArmenian people who may know what it really is reduces to a minimum. The name is not a biblical one like Joseph, Moses or Jacob, having their equivalents in all the languages of the Christian world. Hence the fact that Antranik is an Armenian name becomes of even more importance because the author of course does not mean any Antranik of 
Armenian origin. Here the syntactical structure of the title comes to help the reader (even if he/she does not know who Antranik is) to guess, as soon as the origin of the name has been ascertained, that he is someone merely significant for Armenia and the Armenians. And this is determined by the preposition of in the title. Expressing the sense of possessiveness it determines the cognitive situation where the image itself becomes something belonging to the country and not coming from it (Antranik from Armenia). Thus, the author's intention will be recognized only after the necessary background information is collected for its proper interpretation.

In any case the communicative act between the author and the reader will be successful if communicative context/situation is obviously clear for both communicants otherwise it will be incomplete as the intention encoded in this specific type of utterance will not be recognized. Nonetheless it should be mentioned that in case with the analyzed title the recognition is not absolute because for a non-Armenian reader the image of General Antranik is not of the same value as it is for an Armenian reader that knows who Antranik is and what for he has become a legend and belongs to Armenia. He/she does not need any additional information to read correctly the title and grasp the author's intention to actualize the image of an Armenian legendary hero.

Thus, the cognitive environment is closely interdependent with the image manifestation which comes to establish a certain type of relations and mutual understanding between the author and the reader belonging to the same culture and the same range of image recognition. So the recognition of the author's intention may be complete when the cognitive environment is similar for both the author and the reader as the reality they perceive, reconstruct and reproduce or interpret is one and the same for both of them.

Some of you would probably argue calling for Austin's viewpoint concerning the matter of convention in communicative act. Of course conventionality is also of great importance in communicative situation because as soon as the communicants appear in conventionally designated circumstances they act and react according to certain rules determined by the situation. In literary communication these circumstances are designated by social, national, cultural, area and other conditions. In case with General Antranik neither the selection of language media nor its proper arrangement creates the matter of convention when the reader is a non-Armenian. Conventionality appears only when the reader is an Armenian. It means that even if the intention may be recognized by a nonArmenian reader (due to the background knowledge), the convention cannot be manifested because of deviation in image production and image perception.

\section{References:}

1. Grice, H.P. (1989) Studies in the Way of Words. Cambridge, Mass.: Harvard University Press.

2. Austin, J.L. (1962) How to do things with Words. Cambridge, Mass.: Harvard University Press.

3. Strawson, P.F. (1964) Intention and Convention in Speech acts. // Philosophical Review. Cambridge, Mass.: MIT Press. 
4. Searle, J. (1969) Speech Acts: An Essay in the Philosophy of Language. Cambridge, Eng.: Cambridge University Press.

5. Gasparyan, G. R. (2007) Text and Discourse: Units of Speech and Communicative Activity. // Armenian Folia Anglistika, International Journal of English Studies, 2 (4). Yerevan: Lusakn Publishers.

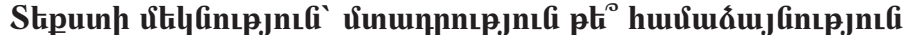

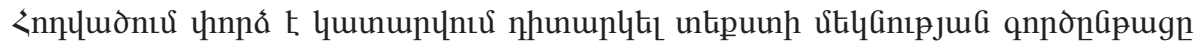

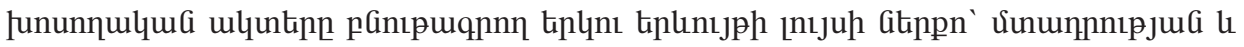

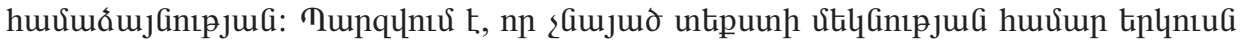

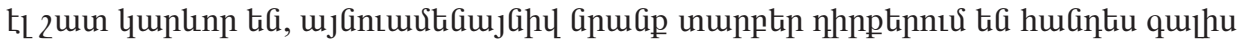
uqqujhG u n乞 uqqujhg nGiptingnnh ntuupntu: 